\title{
Mini Implant as The Anchorage in Skeletal Malocclusion Class II (Case Report)
}

\author{
Chitra Martalia and I Gusti Aju Wahju Ardani \\ Department Ortodonsia Faculty of dentistry, Universitas Airlangga Surabaya Indonesia \\ chitra.martalia@yahoo.com
}

Keywords: $\quad$ Anchorage, En Masse, Face Profile, Mini Implant, Skeletal maloclusion Class II.

\begin{abstract}
A face profile which has disharmony in skeletal maloclusion class II makes it difficult to perform the treatment conventionally with the application of a face mask and head gear. Recently, through the development of technology in dentistry, mini implants have been discovered to correct skeletal maloclusion class II and can be used for maximum anchorage. Objective: This treatment was applied to correct skeletal maloclusion class II by using a mini implant as the anchorage, thereby balancing the face profile. Case: A male patient, 23 years old, had the main complaint that his front teeth were prominent with some gaps between the teeth that caused an unpleasant appearance. The patient admitted that he had a finger sucking habit. Cephalometry showed SNA $83^{\circ}$, SNB $76^{\circ}$, ANB $7^{0}$, NA-APog $9^{0}$ (convex), AB-Npog $-8^{0}$ (skeletal class II), Y line $62^{\circ}$ (normal), interincisal angle $102^{\circ}$ (protrusion), distance I-APog $20 \mathrm{~mm}$ (protrusion), INA angle $42^{\circ}$ (protrusion), I-NB angle $35^{\circ}$ (protrusion), Wits AO-BO $6 \mathrm{~mm}$ (class II), and Naso Labial angle $105^{\circ}$. Clinical examination showed an overjet of $12 \mathrm{~mm}$, overbite of $4 \mathrm{~mm}$, molar and caninus relation class I. Case Management: The application of fixed orthodontic appliance. Anterior upper jaw leveling until Ni-Ti 0,16 0 0,16 in 4 months, the insertion of a mini implant with a diameter of $2 \mathrm{~mm}$ and length of $10 \mathrm{~mm}$ on $1 / 3$ of the apical region of the teeth in regions $16-17$ and $26-27$. One week after the insertion of the mini implant, retraction of the anterior teeth was performed by the en masse technique with a power chain using an archwire SS 0,16 x 0,16. Discussion: After 4 months of the treatment using the mini implant, overjet and diastema decreased. The patient is still being treated. The next treatment is to extract four teeth: premolar 1 of the upper and lower jaw to correct the overjet.
\end{abstract}

\section{INTRODUCTION}

The main factor that determines orthodontic treatment is anchorage. Anchorage is an ability to restrain undesirable movement of the teeth. Anchorage in skeletal malocclusion class II is an important problem for orthodontists in orthodontic treatment. A variety of conventional extra oral appliances to treat skeletal malocclusion class II include face mask and head gear. Extra oral anchorage is limited in its application and some problems occur in the application of these extra oral appliances, including some patients not being cooperative in regard to wearing the appliances because of their difficulty to be used, and they also cause a lack of confidence, so the success rates decrease. Recently through the development of the technology in dentistry, mini implants have been found to provide maximum anchorage to correct skeletal malocclusion class II, so a balanced face profile can be achieved (Bishara, 2001; Feldman, 2006).

Mini implants are available in small sizes made from titanium. Titanium is an excellent metal with fine properties including no allergic reaction, are light, and do not break easily, but they can resist orthodontic force. Mini implants are applied to the alveolar around the apex of the teeth, or depending on the tooth that will be anchored. Mini implants offer stable anchorage that hastens treatments. The application procedure, application, and removal by the orthodontist are also easily performed. They also allow rapid healing and are low-cost. Mini implants are available in diameters of $1.2 \mathrm{~mm}-2 \mathrm{~mm}$ and lengths of 6 - 15 mm (Feldman, 2006; Favero, 2002; Satyawati, 2006).

Mini implants are widely used by orthodontists to achieve a balanced face profile, anterior retraction by the En masse technique, anterior and 
posterior intrusion and extrusion, stabilization of teeth in the region with gross loss of bone, distalization and mesialization of molars, to hold up the molar teeth, and to correct the open bite and deep bite (Young, 2003; Lee, 2007).

Malocclusion is an abnormal relation of the upper and lower jaws. The etiology of malocclusion is divided into two factors, hereditary factors and local factors. Hereditary factors are disproportion of the teeth and jaw size, so malocclusion occurs due to crowded teeth, with multiple diastema, and disharmony of the upper and lower jaw. Local factors are premature loss of deciduous teeth, persistence, and trauma (Singh, 2007; Nanda 2005).

Skeletal malocclusion is caused by disharmony of the maxilla and mandibula in sagittal, vertical, and transversal directions. In malocclusion class II div I, proclination of the upper incisivus muscle causes an increased overjet, deep overbite, hypotonic upper lip, short and incompetent lips, and "V-shaped" jaw. Malocclusion class II div II has a relation with molar class II with characteristics due to the inclination of the central incisivus muscle to the lingual and the inclination of the lateral incisivus muscle to the labium, deep bite, and a "U-shaped" jaw occasionally appears. Malocclusion class II subdivision has a relation with molar class II on one side and class I on the other side. This treatment is applied to correct skeletal maloclusion class II by using mini implants as the anchorage, so balancing of the face profile can be achieved (Proffitt, 2007; Nanda, 2005).

\section{CASE REPORT}

A 23-year-old male patient came to "Rumah Sakit Gigi dan Mulut Universitas Airlangga" with the complaint that the front teeth were prominent with some gaps between them, which caused an unpleasant appearance. The patient admitted he had difficulty closing his lips, and lacked selfconfidence.
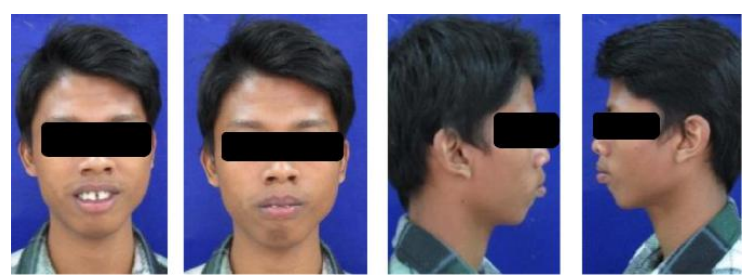

Figure 1: Before treatment. Concave profile, incompetent lips

\subsection{Oral Analysis}

The patient had a concave profile and incompetent lips, but he had normal speech function (Figure 1).

He also had normal oral mucosa tissue and tongue, narrow and deep palate, permanent dentition (Figure 2a), anterior crowding of the lower jaw, a "U-shaped" jaw, rotation of premolars, positive curve of Spee (Figure 2b)

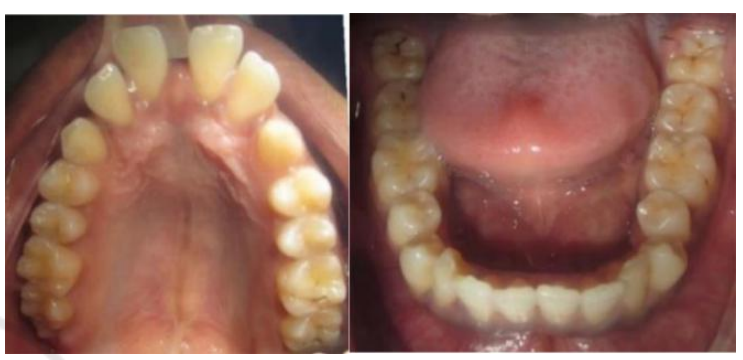

Figure 2a: Anterior diastema, narrow and deep palate; $b$. Anterior crowding

\subsection{Diagnosis}

The patient was diagnosed to have skeletal malocclusion class II. Figure $2 b$ shows that the patient had anterior crowding of the lower jaw and rotation of the right and left premolars. Figure 3a shows midline shifting of the lower jaw $0.5 \mathrm{~mm}$ to the right, and a positive curve of Spee of $5 \mathrm{~mm}$, while Figure $3 \mathrm{~b}$ and $3 \mathrm{c}$ shows anterior diastema of the upper jaw, and molar relation class I on both sides, an overjet of $12 \mathrm{~mm}$, and overbite of $4 \mathrm{~mm}$.

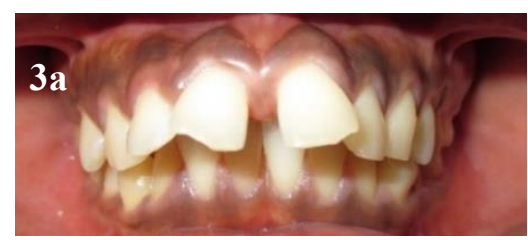

Figure 3a: Intra Oral anterior view; diastema between the central incisors. 

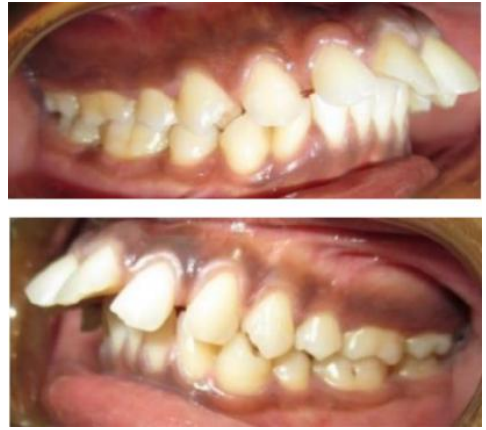

Figure 3b and 3c: Intra Oral. Molar and caninus relation class I, anterior diastema, increased overjet.

\subsection{Etiology}

Skeletal malocclusion class II is caused by hereditary factors. The patient had a finger sucking habit. A narrow and deep palate is caused by the habit of breathing from the mouth. The lower premolar teeth have probably rotated because of the persistence of M2 deciduous teeth.

\subsection{Treatment}

The early treatment was insertion of fixed appliances in the upper and lower jaw (Figure 6). After this, leveling of the anterior upper jaw using Twest Flex and NiTi 0.12 until NiTi 0.16 x 0.16 was performed. After the leveling was corrected, the palate appeared to be broader. Next, leveling of posterior and anterior teeth of the lower jaw with NiTi 0.12 until NiTi 0.14 was performed and archwire SS $0.17 \times 0.25$ was placed on the anterior teeth and on the molar band (double tube). The function of the intrusion arch was for the intrusion of anterior teeth of the mandibular.

The leveling procedure took 4 months. After the teeth were leveled, mini implants with a diameter of $2 \mathrm{~mm}$ and length of $10 \mathrm{~mm}$ were inserted in $1 / 3$ of the apical region of 16-17 and 26-27. One week after the insertion of mini implants, retraction of anterior teeth with archwire SS $0.16 \times 0.16$ was performed (Figure 4).

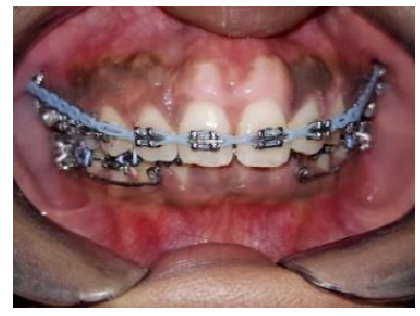

Figure 4. Archwire SS $0.16 \times 0.16,4$ months after the application of mini implants. It shows the decrease of diastema.

Anterior retraction was performed using the En masse technique using a power chain placed on the bracket of the anterior teeth of the upper jaw 13-23. Then the power chain was tied to the mini implant to retract the anterior teeth of the upper jaw, intrude the anterior teeth and close the space of the diastema at the same time (Figure $5 \mathrm{a}$ and $5 \mathrm{~b}$ ). The force of the power chain applied was $200 \mathrm{gr} / \mathrm{mm}$.
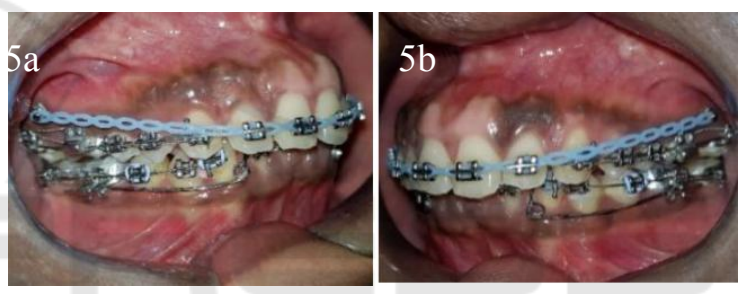

Figure 5a and 5b. 4 months after the placement of mini implants. With anterior retraction by the En masse technique, the overjet decreased. Leveling stage and intrusion arch in the anterior of the lower jaw on the arch.

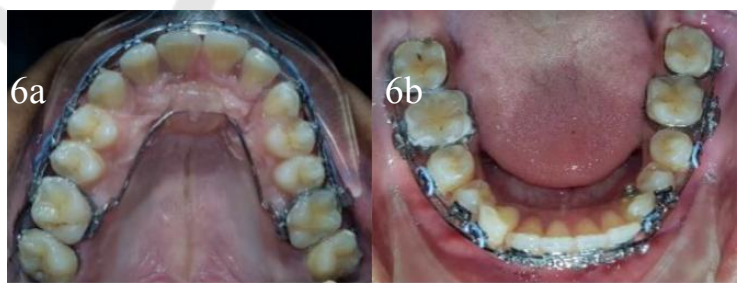

Figure 6a. 4 months after the application of mini implants the diastema decreased; $b$. Leveling and anterior intrusion of the lower jaw. 


\subsection{Radiograph examination}

Table 1. Cephalometry results

\begin{tabular}{|c|c|c|c|}
\hline & Mean & Before & $\begin{array}{l}\text { After } 4 \\
\text { Months }\end{array}$ \\
\hline $\begin{array}{l}\text { The } \\
\text { convexity } \\
\text { degree of the } \\
\text { face } \\
\text { (NA-Apog) }\end{array}$ & $0^{0}$ & $9^{0}$ & $8^{0}$ \\
\hline $\mathrm{AB}-\mathrm{Npog}$ & $-4.6^{0}$ & $-8^{0}$ & $-8^{0}$ \\
\hline $\mathrm{Y}$ axis & $59.4^{0}$ & $62^{0}$ & $60^{0}$ \\
\hline $\begin{array}{l}\text { Interincisal } \\
\text { angle }\end{array}$ & 135.40 & 1020 & 1250 \\
\hline $\begin{array}{l}\text { I-Apog } \\
\text { distance }\end{array}$ & $2.7 \mathrm{~mm}$ & $20 \mathrm{~mm}$ & $11 \mathrm{~mm}$ \\
\hline SNA & 820 & 830 & 830 \\
\hline SNB & 800 & 760 & 760 \\
\hline ANB & 20 & 70 & 70 \\
\hline I -NA degree & 220 & 420 & 12 \\
\hline I -NB degree & 250 & 350 & 420 \\
\hline Wits AO- BO & $-1 \mathrm{~mm}$ & $6 \mathrm{~mm}$ & $2 \mathrm{~mm}$ \\
\hline $\begin{array}{l}\text { Naso Labial } \\
\text { Angle }\end{array}$ & $\begin{array}{c}1,000- \\
1,100 \\
\end{array}$ & 1050 & 1080 \\
\hline $\begin{array}{l}\text { Upper lip to } \\
\text { E-line }\end{array}$ & $2-3 \mathrm{~mm}$ & $8 \mathrm{~mm}$ & $3 \mathrm{~mm}$ \\
\hline $\begin{array}{l}\text { Lower lip to } \\
\text { E-Line }\end{array}$ & $\begin{array}{l}1-2 \\
\mathrm{~mm}\end{array}$ & $12 \mathrm{~mm}$ & $11 \mathrm{~mm}$ \\
\hline
\end{tabular}
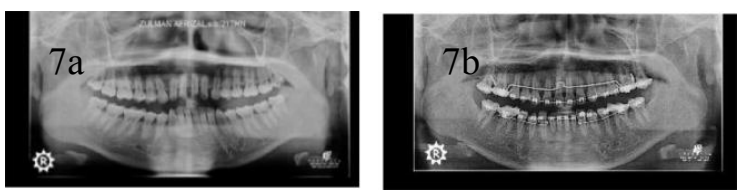

Figure 7: Panoramic a. Before treatment, b. After 8 months of treatment.
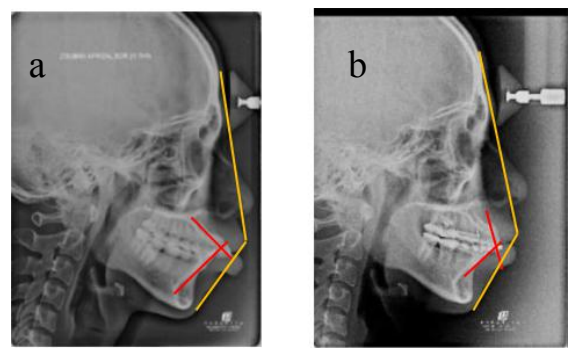

Picture 8: Cephalogram a. Before treatment, b. After 8 months of treatment

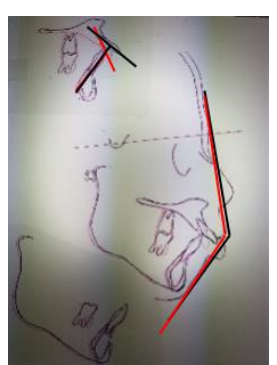

Figure 9: Superimposition. $\square$ Before treatment, Progress of treatment.

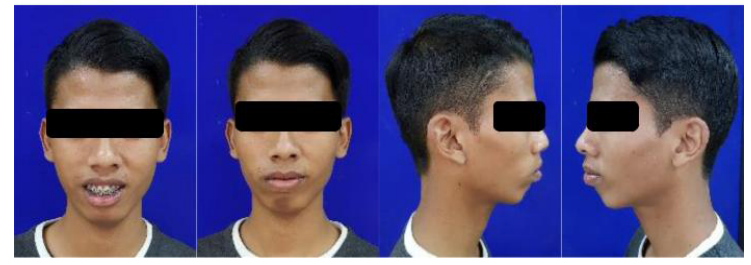

Figure 10 : Progress of treatment

\section{CASE MANAGEMENT}

The application of mini implants with a diameter of 2 $\mathrm{mm}$ and length of $10 \mathrm{~mm}$ was performed. Mini implants were inserted on $1 / 3$ of the apical region of teeth 16-17 and 26-27. Before the application of mini implants, an aseptic procedure with povidone iodine was performed under local anesthesia with pehacain on the mucobuccal fold of teeth region 16-17 and 2627.

Then mini implants were inserted using a hand screwdriver at $60^{\circ}$. After the placement of the mini implants the patient was instructed to maintain oral hygiene and brush his teeth as usual. If there was any complaint, the patient could inform the operator. The patient was instructed to come for a check-up 1 week later.

One week after the placement of the implants, the operator should check the condition of the tissue around the implant to see if there was any sign of inflammation, and to check whether the implants were steady. After the operator was sure that there was no sign of inflammation and no unsteadiness in the implants, the placement of power chain in the bracket of the anterior teeth of the upper jaw 13-23 could be performed. At this stage the patient was asked to visit for check-ups every 3 weeks. 


\section{CONCLUSIONS}

Anchorage is a critical aspect in orthodontic treatment. Anchorage with conventional appliances is troublesome and uncomfortable for the patient. Through the application of mini implants the anchorage is more stable, efficient, and comfortable. In the case of skeletal malocclusion class II, mini implants provide anchorage. Without the application of mini implants, the treatment of skeletal malocclusion class II will take much longer and it is likely that teeth will lose their anchorage.

In this case, there was no complaint or any sign of inflammation around the mini implants. Mini implants can be placed at $45-60^{\circ}$ and there was no loss of anchorage in the application of mini implants. With stabilized anchorage, retraction by the En masse technique can be performed well and rapidly. Four months after the application of mini implants for maximum anchorage, the overjet of the anterior teeth of the upper jaw decreased by $6 \mathrm{~mm}$ and the anterior diastema was corrected by using the mini implants.

The center of resistance can also be defined by its relationship to the force for which the line of action passes through the center of resistance producing a movement of pure translation. It must be noted that, for any given tooth, this movement may be mesiodistal or vestibulolingual, intrusive or extrusive. The position of the center resistance is directly dependent on what may be called the "clinical root" of the tooth.

Currently the patient is still undergoing orthodontic treatment. There are two more treatments in this case. First is the extraction of four teeth: the right-left premolar 1 of the upper and lower jaws to correct the overjet. After this, the next treatment is the use of an intrusion arch of the upper and lower jaw to correct the overbite.

\section{REFERENCES}

Bishara, S.E. 2001. Textbook of Orthodontics. Pennysylvania: W.B. Saunders Comp.

Favero L, Brollo P, Bressan E. 2002. Orthodontic Anchorage with spesific fixture related study analysis. Am.J.Orthod dentofacial orthop. 84-94

Feldsman I, Bondemark L. Orthodontic Anchorage: Systematic Review. Angle Orthod. 2006; 76: 493501
Lee Jong Suk, Kim jung kook, Park Young-Chel, Vanasdall Robert L. 2007. Applications of orthodontic MiniImplants. Canada.,

Nanda Ravindra. 2005. Esthetics and Biomechanics in Orthodontics. $2^{\text {nd }}$ ed.,St.Louis; Elsavier. 77-78

Proffit WR, Fields HW, Sarver DM. 2007. Contemporary Orthodontics. 4th ed., Philadelphia; Elsavier. 201-4

Rahardjo Pambudi. 2012. Ortodonti Dasar edisi 2. Surabaya: Airlangga University Press; $16-18$

Satyawati anak agung A, Anggani HS, Miniimplantsebagaiunit penjangkaran dalam perawatan ortodonti. Indonesian J of Dent. 2006; $31-5$

Singh G. Textbook of Orthodontics. 2007. 2nd. New Delhi: Jaypee Brothers. Medical Publishers

Young CP, Soung YL, Dook HK, Sung HJ. 2003. Intrusions of Posterior Teeth Using Mini-Screw Implant. Am J Orthoddentofacial Orthop. 123; 6904 